\title{
Estimation of Deformational Properties of a Stratum-Borehole System Based on Analysis of Barometric and Tidal Responses of the Water Level in a Borehole
}

\author{
G. N. Kopylova ${ }^{a}$, E. M. Gorbunova ${ }^{b}$, S. V. Boldina ${ }^{a}$, and D. V. Pavlov ${ }^{b}$ \\ ${ }^{a}$ Kamchatka Branch, Geophysical Service, Russian Academy of Sciences, \\ Petropavlovsk-Kamchatski, Russia \\ ${ }^{b}$ Institute of Geosphere Dynamics, Russian Academy of Sciences, \\ Leninskii pr. 38-6, Moscow, 117334 Russia \\ Received December 25, 2008
}

\begin{abstract}
Statically isolated conditions in the stratum-borehole hydrogeological system under consideration at periods of $\geq 3 \mathrm{~h}$ are established on the basis of the investigation of barometric and tidal responses of the water level in a borehole located in the territory of the Mikhnevo Geophysical Observatory, Institute of Geosphere Dynamics, Russian Academy of Sciences. The barometric effectiveness, tidal sensitivity of the water level, elastic parameters, and porosity of water-bearing rocks are estimated. A model of the inertial character of the water exchange in the stratum-borehole system is constructed depending on the period of variations with allowance for the borehole design, as well as the water transmissibility and elastic capacity of the aquifer. The results of modeling are in compliance with the dependence of the amplitude transfer function from variations in the atmospheric pressure to variations in the water level. The results of processing the data of high-precision measurements made it possible to refine the transmissibility of the aquifer obtained from the data of experimental filtration works.
\end{abstract}

PACS numbers: 91.45.Xz

DOI: $10.1134 / \mathrm{S} 1069351309100073$

\section{INTRODUCTION}

High-precision observations of variations in the groundwater level form a traditional component of the system of geophysical monitoring aimed at the diagnostics of the stress-strain state of the geological medium. In seismically active regions of Russia (the Far East, the Transbaikal region, the North Caucasus), such measurements have been conducted during recent decades in the search for earthquake precursors [Kopylova et al., 2007]. In aseismic regions of Russia, predominantly within the Moscow artesian basin (MAB), high-precision level-gauge observations were performed periodically and were mainly aimed at the study of tidal response of the water level in boreholes [Lyubushin et al., 1997; Bagmet et al., 1989].

High-precision level-gauge observations synchronous with measurements of the atmospheric pressure at the nearmouth site have been conducted since February 2008 in a borehole located in the territory of the Mikhnevo Geophysical Observatory of the Institute of Geosphere Dynamics of the Russian academy of Sciences (Mikhnevo GO IDG RAN). The obtained series of data was used for the study of barometric and tidal responses of the water level and the estimation of the inertial character of the water exchange in the stratum-borehole system in order to identify the frequency range of the signal recording, which contains the information needed for determining the deformation of water-bearing rocks of the reference aquifer.

\section{SCIENTIFIC-METHODOLOGICAL EXPERIENCE IN THE PROCESSING OF THE RESULTS OF HIGH-PRECISION LEVEL-GAUGE MEASUREMENTS}

In aseismic regions, responses to the elastic deformation of water-bearing rocks caused by permanently acting factors of the atmospheric load and lunisolar tides can manifest themselves in water-level variations in boreholes that open pressure aquifers.

If a borehole opens an isolated aquifer, in which the water filtration may be neglected, and the water exchange between saturated rocks and the borehole shaft does not distort the level response to pore pressure variations, the level response, whose amplitude $\Delta h_{b}$ is linearly related to the vertical barometric load $\Delta b$ by the following expression:

$$
\Delta h_{b}=-\left(1 / \rho_{\mathrm{w}} g\right)\left[1-(B / 3)\left(1+v_{u}\right) /\left(1-v_{u}\right)\right] \Delta b .
$$

will correspond to variations in the atmospheric pressure.

Tides in the solid Earth are accompanied by the volume strain of water-bearing rocks. In this case, the amplitude of 
the tidal response of the water level in the borehole $\Delta h_{t}$ is proportional to the strain amplitude $\Delta \varepsilon$ :

$$
\Delta h_{t}=-\left(1 / \rho_{\mathrm{w}} g\right)(2 G B / 3)\left[\left(1+v_{u}\right) /\left(1-2 v_{u}\right)\right] \Delta \varepsilon,
$$

where $\rho_{\mathrm{w}}$ is the water density, and $g$ is the gravitational acceleration. The coupling coefficients in (1) and (2) are controlled by elastic parameters of the reservoir, such as the shear modulus $G$, the Skempton coefficient $B$, and the Poisson ratios for nondrained conditions $v_{u}$ [Roeloffs, 1988].

In the practice of level-gauge observations, the barometric effectiveness $E_{b}=-\Delta h_{b} / \Delta b$ and its dependence on the period of variations are used for characterizing the barometric response of the level. If constant values of $E_{b}$ are found in a certain range of periods, this means that in this range, the water exchange between the borehole and saturated rocks, as well as filtration processes, do not distort the manifestations of the barometric response of the water level. The range of the periods of the variations of the water-level, representative for the determination of the tidal response and strain-metering properties of the stratumborehole observation system, is estimated within the static value of barometric effectiveness.

The amplitudes of some tidal waves are identified, and phase relations between tidal variations in the level and the corresponding components of the tidal gravitational potential are estimated in order to characterize the tidal action in filtered series of water-level measurements after eliminating the effect of barometric load. The tidal sensitivity of the water level $A_{V}$ with respect to the theoretical or experimentally recorded tidal strain of rocks can be calculated from the relation:

$$
A_{V}=-\Delta h_{t} / \Delta \varepsilon,
$$

where $\Delta h_{t}$ is the amplitude of tidal variations in the water level $(\mathrm{cm})$, and $\Delta \varepsilon$ is the amplitude of tidal variations in the volume strain $\left(10^{-9}\right)$.

The detection of a statically isolated response of the water level in boreholes of the observation network and the estimation of its parameters, i.e., the range of periods and the tidal sensitivity of the water level, are considered as an important indicator of the information content of levelgauge observations in the works [Kopylova, 2006; Kopylova et al., 2007; Rojstaczer, 1988; Rojstaczer and Agnew, 1989]. The identified statically isolated response of the water level is linearly related to the strain of the aquifer and, depends on the elastic parameters of rocks in accordance with (2).

In the high-frequency region, the range of periods of a statically isolated response of the water level is restricted due to the inertial properties of the stratum-borehole system caused by the presence of a nonzero water mass in the borehole shaft. In order that water-level variations could completely reflect pore-pressure variations, it is necessary to determine the interval of periods corresponding to the regime of stabilization (equilibrium) of the stratum-borehole hydrogeological system, which depends on the borehole design and filtration properties of water-bearing rocks.
A mathematical model of water-level variations in a borehole at harmonic pore-pressure variations with allowance for the borehole design (radii of the cased and open parts of the borehole shaft, $r_{c}$ and $r_{w}$, respectively), as well as water transmissibility $T$, and elastic capacity of waterbearing rocks $S$, was proposed in [Hsieh et al., 1987]. The mathematical model under consideration is based on the estimation of the dependences of the amplitude ratio and the phase shift between pressure variations in the aquifer and the water level in the borehole on the period of variations. For some boreholes, this model adequately describes inertial character of the water exchange in the stratumborehole system in the cases, when the barometric load changes [Boldina and Kopylova, 2006].

In a low-frequency region, the boundary of a statically isolated response of the water level is controlled mainly by hydrogeological conditions, namely, the periodicity and intensity of groundwater supply, filtration properties of water-bearing rocks, and parameters of the underground stream (velocity, flow rate) [Kopylova, 2006; Rojstaczer, 1988].

For boreholes that open isolated pressure aquifers, the range of periods, at which a statically isolated response of the water level manifests itself, can vary widely: from minutes to a few hours to days to tens of days. In this range, water-level variations can contain variations corresponding to changes in the stress-strain state of the aquifer caused by geodynamic activation of the geological medium.

\section{METHODS OF INVESTIGATIONS}

In this work, we estimate strain-metering and hydrogeological parameters of an aquifer opened by an observation borehole located within an aseismic region on the basis of the study of the water-level response to the barometric and tidal actions. With this purpose, we performed the cross-spectral analysis of variations in the water level and atmospheric pressure in order to determine the barometric effectiveness $E_{b}$ and its dependence on the period of variations, as well as the tidal analysis of water-level variations in the range of periods $2-30 \mathrm{~h}$ in accordance with the ETERNA 3.0 program [Wenzel, 1994], allowing us to estimate the tidal sensitivity of the water level with respect to the theoretical values of the volume and areal strains.

For statically isolated conditions in the stratum-borehole system, we determined the elastic parameters of water-bearing rocks and porosity with the use of formulas of the poroelasticity theory [Rojstaczer and Agnew, 1989]. The filtration and elastic parameters of the aquifer were also estimated from the data of experimental-filtration works and the results of analysis of the tidal and barometric responses of the water level in the borehole. The results of the modeling of the inertial character of the water exchange in the stratum-borehole system obtained in accordance with [Hsieh et al., 1987] were compared with variations in the barometric effectiveness, depending on the period of the variations and the hydrogeological parameters calculated from the data gathered from the borehole tests. 


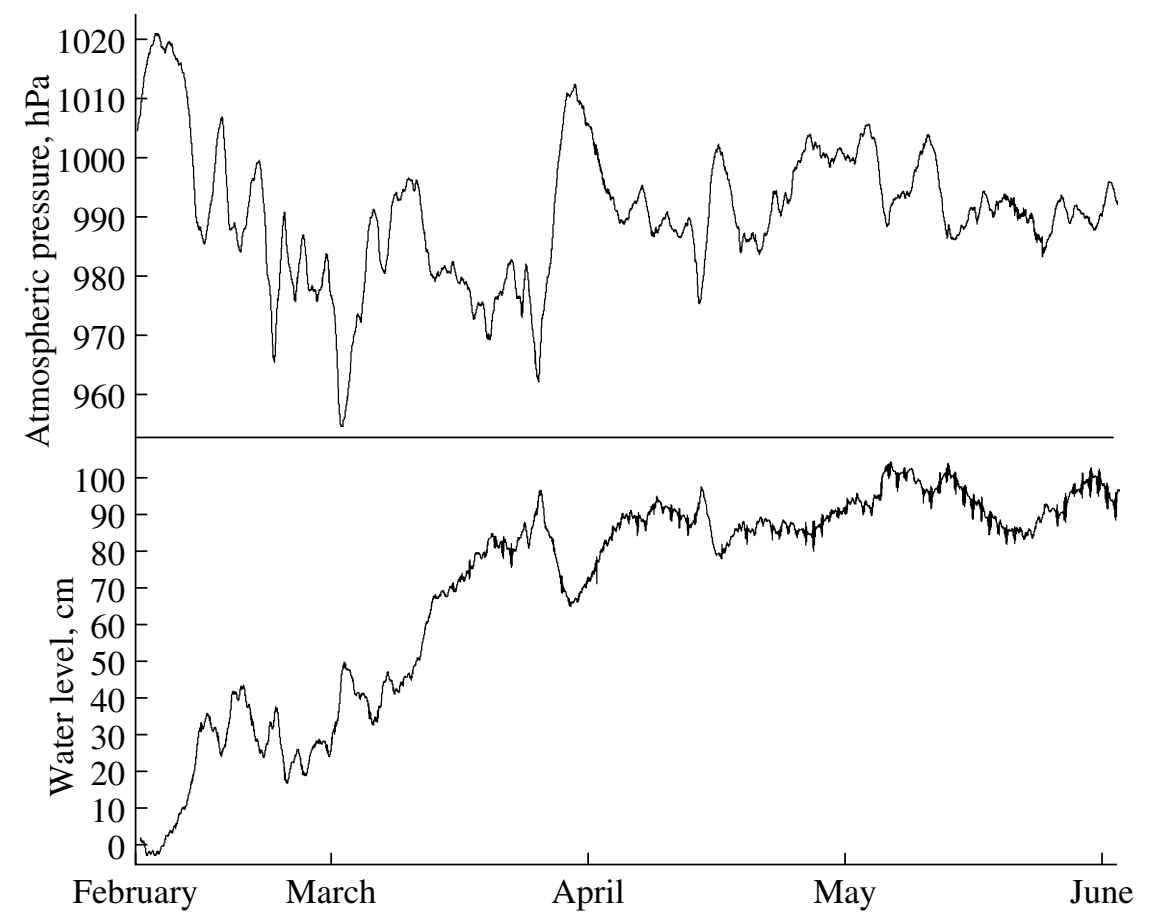

Fig. 1. Water-level and atmospheric-pressure variations in borehole No. 2 from February 6 through June 2, 2008.

\section{CHARACTERIZATION OF THE BOREHOLE AND OBSERVATIONAL DATA}

High-precision measurements of level variations in borehole No. 2 were conducted in the territory of the Mikhnevo GO IDG RAN, located $3 \mathrm{~km}$ west of Pochinki village, Stupino district, Moscow oblast. Borehole No. 2 (coordinates $54.96^{\circ} \mathrm{N}, 37.77^{\circ} \mathrm{E}$, borehole-mouth elevation $167.5 \mathrm{~m}$ ) was equipped with an LMP $308 \mathrm{i}$ (Germany) submersible sonde with the measurement accuracy of waterlevel variations of $0.5 \mathrm{~mm}$ and a sampling periodicity of $1 \mathrm{~s}$. In the interval 0-91 m, the borehole was cased by a column of metallic pipes $127 \mathrm{~mm}$ in diameter. Below, to a depth of $115 \mathrm{~m}$, the borehole shaft $118 \mathrm{~mm}$ in diameter was open and in contact with water-bearing rocks.

Stationary observations of level variations in the Aleksin-Tarusa pressure aquifer opened in the interval 76.1$115 \mathrm{~m}$ have been conducted. This aquifer is presented by the fissured limestones of the Lower-Carboniferous age with interlayers of clays and marls. The horizon of clays of the Middle-Carboniferous age, $19.5 \mathrm{~m}$ thick, is an overlapping aquifuge, which separates sandstones from the overlying formation composed of the carbonate-terrigenous deposits of the Middle-Carboniferous age, as well as the aqueo-glacial and morainic deposits of the Quaternary age.

The water level in the borehole has been established at a depth of $68 \mathrm{~m}$ with an excessive pressure of $8.1 \mathrm{~m}$ within the Aleksin-Terusa aquifer with respect to the top. The radius of the casing string in the zone of groundwater-level variations is $r_{c}=0.064 \mathrm{~m}$, and in the interval of the waterreceiving part of the borehole, $r_{w}=0.059 \mathrm{~m}$.
After the completion of drilling, a complex of geophysical investigations and experimental-filtration works was performed in borehole No. 2 . The water transmissibility $T$ of the opened sequence of the Aleksin-Tarusa aquifer up to $38.9 \mathrm{~m}$ thick, according to the data of flow-metering and experimental filling, does not exceed $2.1 \mathrm{~m}^{2} /$ day and, according to the data of pumping, $4.0 \mathrm{~m}^{2} /$ day. In the intervals of water inflow 92-94 and 99-100 m identified from the results of flow-metering, the water transmissibility attains $13 \mathrm{~m}^{2} /$ day. According to the data of three methods of experimental-filtration investigations, the filtration coefficient $k$ within the opened sequence lies in the range 0.06$0.16 \mathrm{~m} /$ day. According to the data of express testing of the Aleksin-Tarusa aquifer, the piezo-transmissibility $a$ and the elastic yield of water $\mu^{*}$ are $1.3 \times 10^{-4} \mathrm{~m}^{2} /$ day and $2.3 \times$ $10^{-4}$, respectively.

A fragment of the data of continuous observations of the variations in the water level and atmospheric pressure in the period from February 6 through June 2, 2008, with their averaging in the $100 \mathrm{~s}$ window is presented in Fig. 1. Barometric variations synchronously repeating variations in the atmospheric pressure, as well as the seasonal trend with its amplitude of about $1 \mathrm{~m}$, are traceable in water-level variations. In addition, anthropogenic noise is periodically present in water-level variations. The amplitude of level variations during the appearance of this noise attains 4.0$6.5 \mathrm{~cm}$, and the noise duration lasts for several hours. In atmospheric-pressure records, this noise appears rarely; its amplitude is weakened and does not exceed $1.5 \mathrm{hPa}$.

To suppress the influence of noise on barometric and tidal variations in the water level, we passed from the aver- 


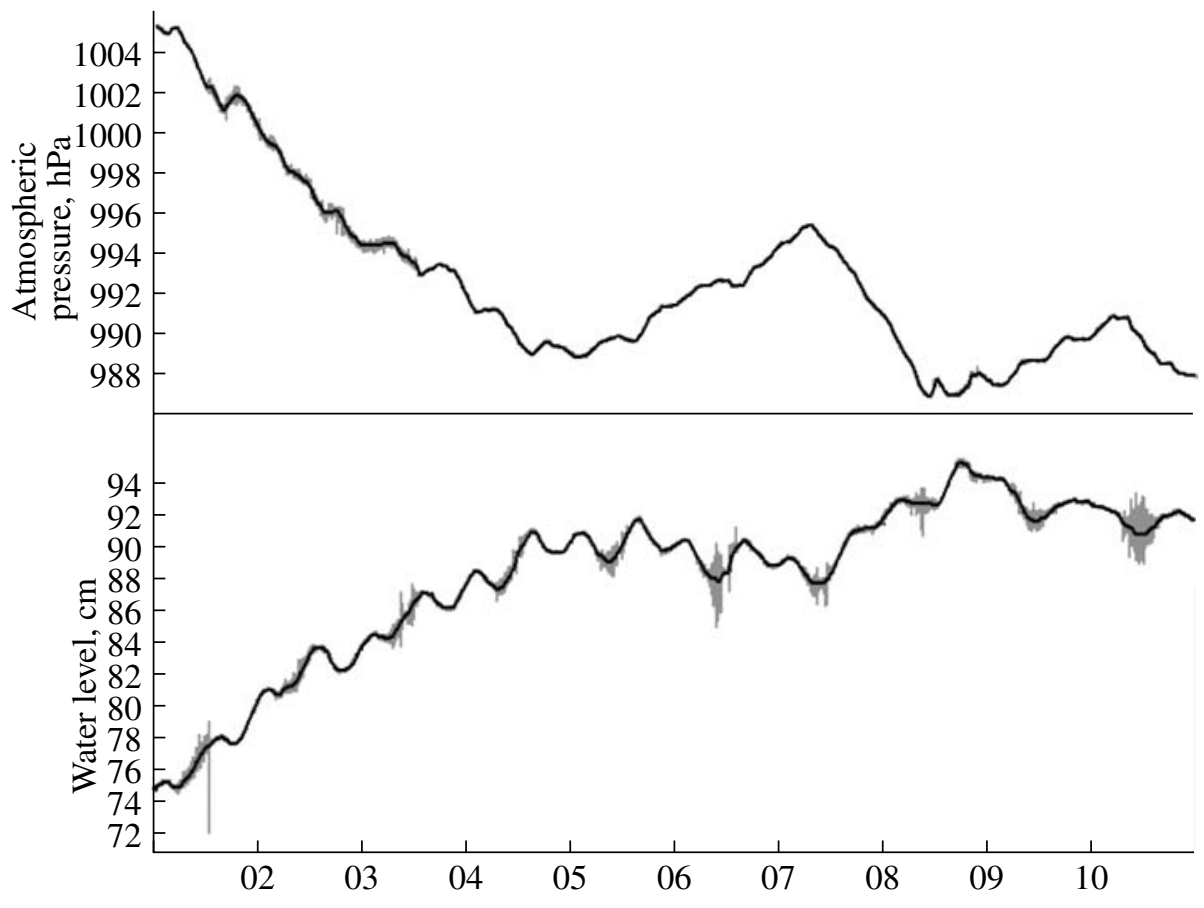

Fig. 2. Variations in hourly mean values of the atmospheric pressure and the water level in borehole No. 2 from April 1 through April 10, 2008 (indicated by thick black lines), superposed on 100-s variations (indicated by gray lines).

aging of data over $100 \mathrm{~s}$ to their averaging over $1 \mathrm{~h}$. A fragment of hourly mean variations in the water level and atmospheric pressure obtained through the averaging of 100-s data in a window containing 36 counts with a step equal to 36 counts is presented in Fig. 2. This procedure satisfactorily compensates the noise in the hourly mean data. In addition, diurnal and semidiurnal variations of the earth-tide's origin become more clearly pronounced in water-level variations compared with the initial records. The obtained time series of hourly mean values of the water level and atmospheric pressure were used for the determination of parameters of the barometric and tidal responses of the water level in borehole No. 2 .

\section{BAROMETRIC RESPONSE OF THE WATER LEVEL}

The parameters of the barometric response of the water level were estimated by the method of cross-spectral analysis [Lyubushin, 2007]. For this purpose, we constructed a cross-periodogram of two scalar time series: the input signal $X(t)$, i.e., the atmospheric pressure, and $Y(t)$, i.e., the water level, averaged in the moving window of $256 \mathrm{~h}$. Before calculating the cross-periodogram, we passed from the initial hourly mean time series $X(t)$ and $Y(t)$ to their first differences in order to suppress the low-frequency trends in both signals.

Frequency bands in the intervals of semidiurnal and diurnal periods $11-13$ and $23-27 \mathrm{~h}$ were preliminarily eliminated from the initial time series $X(t)$ and $Y(t)$ with the use of the ideal filter. From the averaged cross-periodogram of the series $X(t)$ and $Y(t)$, we performed a non- parametric estimation of the functions of the squared module of the coherence spectrum, the amplitude transfer function (ATF) from atmospheric-pressure variations to waterlevel variations, and the cosine of the phase difference depending on the period of the variations (Fig. 3).

The upper plot of Fig. 3 characterizes the coherence of the variations in the atmospheric pressure and water level depending on the period. It is seen that the coherence smoothly increases from 0.2 to its maximum value of 0.89 in the range of periods from $2 \mathrm{~h}$ to about $8 \mathrm{~h}$. Such an increase is caused, on the one hand, by the inertial effect of the water exchange in the stratum-borehole system and the weakening of the water-level response to the barometric load at relatively small periods and, on the other hand, by the presence of noise variations in both time series, which decrease the stability of the estimated coherence.

Three intervals are recognizable in the behavior of the ATF from atmospheric-pressure variations to water-level variations (middle plot in Fig. 3): (1) a rapid increase from 0.58 to $0.66 \mathrm{~cm} / \mathrm{hPa}$ in the range $2-3 \mathrm{~h}$; (2) unstable behavior with variations from 0.66 to $0.68 \mathrm{~cm} / \mathrm{hPa}$ in the range $3-$ $10 \mathrm{~h}$; and (3) stabilization at the value $0.65 \mathrm{~cm} / \mathrm{hPa}$ in the range of periods $\geq 11 \mathrm{~h}$. Such behavior of the ATF shows that inertial character of the water exchange in the stratumborehole system has a substantial influence only at small periods of the formation of the barometric response of the level, which do not exceed $3 \mathrm{~h}$. The presence of the instability segment is associated either with the specific features of the formation of the barometric response of the water level in borehole No. 2 or with the effects of the noise. 

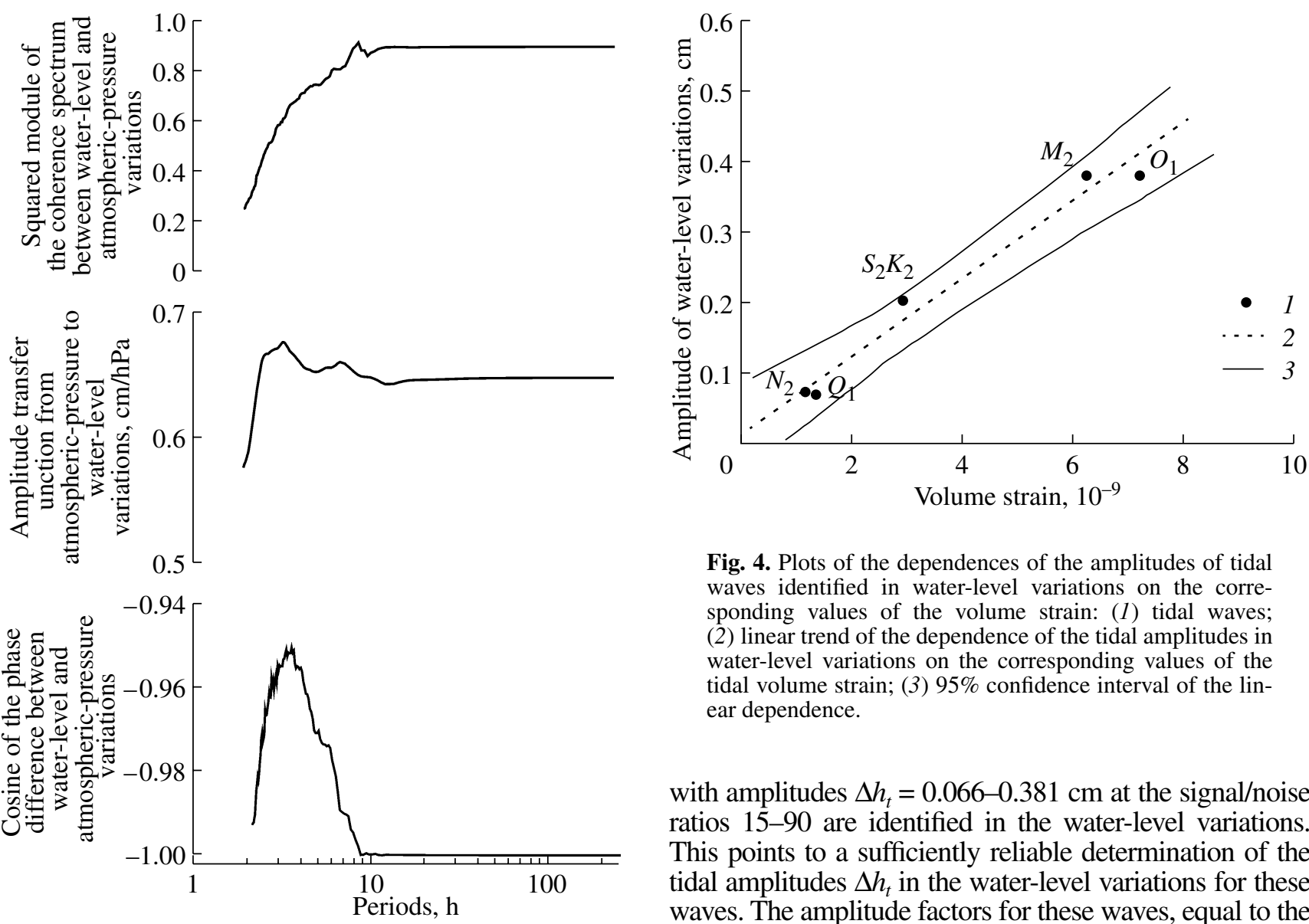

Fig. 4. Plots of the dependences of the amplitudes of tidal waves identified in water-level variations on the corresponding values of the volume strain: (1) tidal waves; (2) linear trend of the dependence of the tidal amplitudes in water-level variations on the corresponding values of the tidal volume strain; (3) $95 \%$ confidence interval of the linear dependence.

Fig. 3. Results of the cross-spectral analysis of hourly mean variations in the water level and atmospheric pressure.

The barometric effectiveness $E_{b}$ characterizing an isolated response of the level to the barometric load is estimated from the ATF's behavior [Kopylova, 2006]. The value $E_{b}=0.65 \mathrm{~cm} / \mathrm{hPa}$ at periods $\geq 3 \mathrm{~h}$ is assumed to be characteristic of the barometric response of the water level in borehole No. 2 for statically isolated conditions. The phase difference between variations in the water level and atmospheric pressure in the range of periods under consideration is $-160^{\circ} \ldots-180^{\circ}$, and it attains a stable value $-180^{\circ}$ at periods of $\geq 8 \mathrm{~h}$ (lower plot in Fig. 3).

The results of the barometric analysis show that the total barometric response of the water level in borehole No. 2 takes place at periods $\geq 3 \mathrm{~h}$ and is characterized by the barometric effectiveness $E_{b}=0.65 \mathrm{~cm} / \mathrm{hPa}$. The presence of statically isolated conditions in the stratum-borehole system can be presumed to exist in the range of periods from $3 \mathrm{~h}$ to approximately a few hundreds of hours.

\section{TIDAL RESPONSE OF THE WATER LEVEL}

The results of the tidal analysis of water-level variations in borehole No. 2 are presented in Table 1. The names of the tidal waves correspond to those given in [Melchior, 1968]. Five powerful tidal waves $Q_{1}, O_{1}, N_{2}, M_{2}$, and $S_{2} K_{2}$

with amplitudes $\Delta h_{t}=0.066-0.381 \mathrm{~cm}$ at the signal $/$ noise ratios 15-90 are identified in the water-level variations. This points to a sufficiently reliable determination of the tidal amplitudes $\Delta h_{t}$ in the water-level variations for these waves. The amplitude factors for these waves, equal to the ratio of the amplitudes $\Delta h_{t}$ identified in the water-level variations to the corresponding values of the volume strain $\Delta \varepsilon$ are $0.048-0.069 \mathrm{~cm} / 10^{-9}$. Good estimates of the phase difference between the waves in water-level variations and the corresponding components of the tidal gravitational potential (i.e., close to $-180^{\circ}$ ) are also obtained for all of the five waves. The results of estimations for the $P_{1} S_{1}$ wave, whose period is closest to the diurnal period, are not considered in what follows due to the strong noise of the water-level variations by the action of meteorological factors in the diurnal period.

The plot of the dependence of the amplitudes identified in water-level variations of the five tidal waves on the corresponding values of the theoretical volume strain is presented in Fig. 4. Linear dependence with a 95\% confidence probability and a correlation coefficient of $R=0.99$ is described by the equation:

$$
\Delta h_{t}=(0.056 \pm 0.002) \Delta \varepsilon+(0.010 \pm 0.047)
$$

The slope of the linear dependence $0.056 \pm$ $0.002 \mathrm{~cm} / 10^{-9}$ characterizes the tidal response of the water level in borehole No. 2 in the entire range of the diurnal and semidiurnal tides and is assumed to be the tidal sensitivity of the water level $A_{V}$ with respect to the volume strain of water-bearing rocks.

To calculate the elastic parameters and porosity of water-bearing rocks according to [Rojstaczer and Agnew, 1989], we also estimated the amplitude factors for individ- 
Table 1. Results of tidal analysis of water-level variations in borehole No. 2 in accordance with the ETERNA 3.0 program [Wenzel, 1994]

\begin{tabular}{|c|c|c|c|c|c|}
\hline $\begin{array}{c}\text { Wave, period, } \\
\mathrm{h}\end{array}$ & $\begin{array}{l}\text { Amplitude of volume } \\
\text { strain } \Delta \varepsilon, 10^{-9}\end{array}$ & $\begin{array}{c}\text { Amplitude of water } \\
\text { level, } \Delta h_{t}, \mathrm{~cm}\end{array}$ & Signal/noise & $\begin{array}{l}\text { Amplitude factor, } \\
\mathrm{cm} / 10^{-9}\end{array}$ & Phase shift, deg \\
\hline $\begin{array}{l}Q_{1} \\
26.87\end{array}$ & 1.38 & 0.066 & 15.9 & $0.048 \pm 0.020$ & $-177 \pm 24$ \\
\hline $\begin{array}{l}O_{1} \\
25.82\end{array}$ & 7.18 & 0.381 & 89.8 & $0.053 \pm 0.004$ & $-178 \pm 4$ \\
\hline $\begin{array}{l}M_{1} \\
24.83\end{array}$ & 0.56 & 0.024 & 4.9 & $0.042 \pm 0.048$ & $-134 \pm 65$ \\
\hline $\begin{array}{l}P_{1} S_{1} \\
23.93\end{array}$ & 10.10 & 0.393 & 81.6 & $0.039 \pm 0.003$ & $-155 \pm 4$ \\
\hline $\begin{array}{l}J_{1} \\
23.10\end{array}$ & 0.56 & 0.012 & 2.9 & $0.021 \pm 0.048$ & $-172 \pm 133$ \\
\hline $\begin{array}{l}O O_{1} \\
22.31\end{array}$ & 0.31 & 0.014 & 4.9 & $0.046 \pm 0.088$ & $-174 \pm 111$ \\
\hline $\begin{array}{l}2 \mathrm{~N}_{2} \\
12.87\end{array}$ & 0.19 & 0.010 & 2.6 & $0.052 \pm 0.038$ & $-131 \pm 42$ \\
\hline $\begin{array}{l}N_{2} \\
12.66\end{array}$ & 1.19 & 0.071 & 14.9 & $0.060 \pm 0.006$ & $-178 \pm 6$ \\
\hline $\begin{array}{l}M_{2} \\
12.42\end{array}$ & 6.24 & 0.381 & 76.5 & $0.061 \pm 0.001$ & $-179 \pm 1$ \\
\hline $\begin{array}{l}L_{2} \\
12.19\end{array}$ & 0.18 & 0.006 & 1.1 & $0.032 \pm 0.041$ & $-146 \pm 73$ \\
\hline $\begin{array}{l}S_{2} K_{2} \\
12.00\end{array}$ & 2.90 & 0.201 & 47.9 & $0.069 \pm 0.002$ & $-170 \pm 2$ \\
\hline
\end{tabular}

Note: (1) Waves in water-level variations at signal/noise ratios $\geq 10$ are bold-faced; (2) the regression coefficient of the relation between water-level and atmospheric-pressure variations at periods of $2-30 \mathrm{~h}$ is $0.652 \pm 0.005 \mathrm{~cm} / \mathrm{hPa}$.

ual waves with respect to the areal tidal strain, equal to the sum of two of its horizontal components with the use of the tidal analysis of level-gauge data in accordance with the ETERNA 3.0 program. The obtained tidal sensitivity of the water level with respect to the areal strain is $A_{s}=$ $0.037 \mathrm{~cm} / 10^{-9}$.

\section{ESTIMATION OF THE ELASTIC PARAMETERS AND POROSITY OF WATER-BEARING ROCKS}

It is assumed in the model used that water-bearing rocks form a relatively isolated water-saturated stratum composed of a porous elastic material with an active (open) porosity. Such natural objects, provided they are homogeneous and isotropic under isothermal conditions, can be described by the linear theory of poroelasticity [Rice and Cleary, 1976], which includes the system of equations relating strain and stress variations in the rock skeleton with allowance for the skeleton's compressibility and elastic variations in the water volume.

The formula for calculating the drained (at a constant pore pressure) compressibility of the skeleton with allowance for the pores $\beta$, Skempton coefficient $B$, shear modulus $G$, and porosity of water-bearing rocks $\phi$ are presented in [Rojstaczer and Agnew, 1989; Kopylova and Boldina, 2006] as applied to the stratum-borehole system, for which a statically isolated response of the water level is established and the barometric effectiveness $E_{b}$ and the tidal sensitivity $A_{s}$ are determined. In this case, the tabulated values of the water compressibility $\beta_{f}$ and the compressibility of the solid phase of the skeleton $\beta_{s}$ are assumed to be known. It is also assumed that the values of $\beta_{s}$ (compressibility of the solid phase of the skeleton) and $\beta_{u}$ (nondrained (at a constant mass of the fluid) compressibility of the skeleton with allowance for pores) are approximately equal to each other. The specific elastic capacity of water-bearing rocks $S_{s}$ is determined as $S_{s}=\rho g\left(\beta+\phi \beta_{f}\right)$.

The values of the elastic parameters and porosity of the Aleksin-Tarusa aquifer are indicated in Table 2. These values are calculated for a statically isolated response of the water level in borehole No. 2 in accordance with [Rojstaczer and Agnew, 1989; Kopylova and Boldina, 2006] at the nondrained compressibility $\beta_{u}=0.3 \times 10^{-10} \mathrm{~Pa}^{-1}$, water compressibility $\beta_{f}=4.4 \times 10^{-10} \mathrm{~Pa}^{-1}$, and characteristic Poisson ratio $v=0.25$. The elastic capacity of the aquifer $S$ was calculated by the formula $S=S_{s} m$, where $m$ is the opened thickness of the Aleksin-Tarusa aquifer (24.0$38.9 \mathrm{~m}$ ), and is equal to $0.9-1.4 \times 10^{-4}$. The value of $S$ approximately corresponds to the elastic yield of water $\mu^{*}=2.3 \times 10^{-4}$ obtained from the data of the express filling of the borehole. 
Table 2. Calculated values of elastic parameters and porosity of water-bearing rocks

\begin{tabular}{c|c|c|c|c|c|c}
\hline $\begin{array}{c}\text { Barometric } \\
\text { effectiveness } E_{b}, \\
\mathrm{~cm} / \mathrm{hPa}\end{array}$ & $\begin{array}{c}\text { Tidal sensitivity } \\
\text { of water level } \mathrm{A}_{s}, \\
\mathrm{~m} / 10^{-7}\end{array}$ & $\begin{array}{c}\text { Drained compress- } \\
\text { ibility of skeleton } \beta, \\
\mathrm{Pa}^{-1} \times 10^{-11}\end{array}$ & $\begin{array}{c}\text { Shear modulus } \\
G, \mathrm{~Pa} \times 10^{10}\end{array}$ & $\begin{array}{c}\text { Skempton } \\
\text { coefficient } B\end{array}$ & $\begin{array}{c}\text { Specific elastic } \\
\text { capacity } S_{s}, \\
\mathrm{~m}^{-1} \times 10^{-7}\end{array}$ & $\begin{array}{c}\text { Porosity } \phi \\
0.65\end{array}$ \\
0.037 & 16.2 & 0.37 & 0.40 & 36.9 & 0.49 \\
\hline
\end{tabular}

\section{ESTIMATION OF THE INERTIAL CHARACTER OF THE WATER EXCHANGE IN THE STRATUM-BOREHOLE SYSTEM}

When the barometric and tidal actions on the behavior of an isolated aquifer are considered, the lateral filtration of the underground stream can be neglected, because a significant spatial radius of action of the specified factors suggests the absence of horizontal gradients of the pore pressure. In addition, with the complete isolation of the Aleksin-Tarusa aquifer by the regional aquifuge (virtually impermeable clays), the vertical cross flow from the overlying aquifer is excluded. This inference is supported by the data of stationary observations of hydrodynamic parameters of the overlying Kashira aquifer and the Aleksin-Tarusa aquifer, which are characterized by the difference of heads attaining $43.2 \mathrm{~m}$.

In this case, at any periodical disturbance of the pore pressure with the amplitude $p_{0}$ at sufficiently long periods, the water level in the borehole $x_{0}$ will reflect the pressure in the stratum $h_{0}$ as

$$
x_{0}=p_{0} / \rho_{\mathrm{w}} g=h_{0} .
$$

However, at relatively small periods of pore-pressure variations in the aquifer, the peak value of the water level will be smaller than that determined in accordance with (5) and will lag with respect to the peak of the pressure $h_{0}$ due to the inertial character of the water exchange in the stratum-borehole system. In this case, the amplitude ratio (ratio of the amplitudes of variations in the water level in the borehole and in the hydrostatic pressure in the aquifer) is calculated as $A=x_{0} / h_{0}$, and the phase shift is calculated as $\eta=\arg \left(x_{0} / h_{0}\right)$.

The dependences of the parameters $A$ and $\eta$ on the period of variations in the pore pressure with allowance for the filtering and elastic properties of water-bearing rocks and the borehole design characterize the degree of inertia of the water exchange in the stratum-borehole system under consideration. The expressions for a periodic lowering of the water level in the borehole, the amplitude ratio, and the phase shift with allowance for the water transmissibility $T$, the elastic capacity of water-bearing rocks $S$, and the borehole radii in the zone of water-level variations $r_{c}$ and in the water-receiving part of the borehole $r_{w}$ are presented in the works [Hsieh et al., 1987; Boldina and Kopylova, 2006]. The theoretical dependences of the amplitude ratio and phase shift derived in [Hsieh et al., 1987] can also be used for a more exact determination of the water transmissibility of the aquifer $T$.
The plots of the amplitude ratio $A$ and the phase shift $\eta$ at different values of $T \tau / r_{c}^{2}$, where $\tau$ is the period of variations (in seconds), and $S r_{w}^{2} / r_{c}^{2}$ for borehole No. 2 are presented in Figs. 5 and 6. The calculated value $S=1 \times 10^{-4}$ obtained from the results of analysis of the barometric and tidal responses of the water level was used for constructing the plot in Fig. 5. In this case, the water transmissibility $T$ was determined by selecting from the condition of the best correspondence between the result of the modeling of the inertial effect of the water exchange and the behavior of the amplitude transfer function from atmospheric-pressure
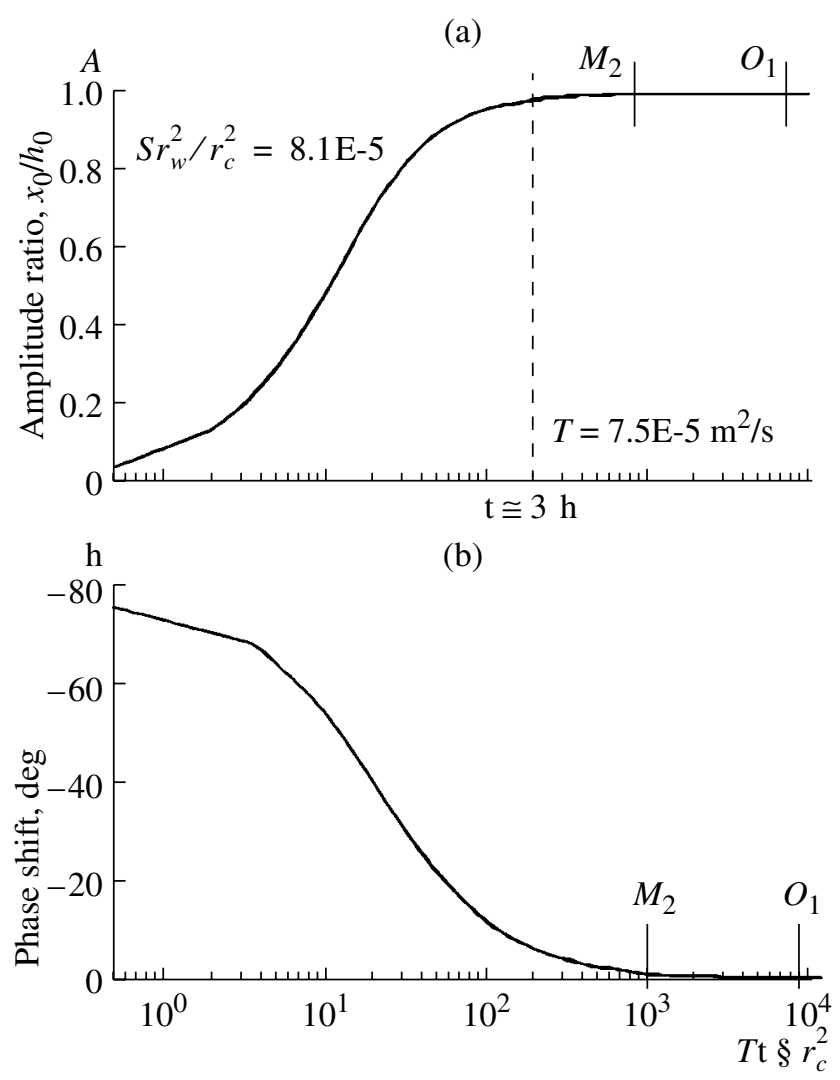

Fig. 5. Plots of (a) the amplitude ratio $x_{0} / h_{0}$ and (b) the phase shift $\eta$ between the water-level variations in borehole No. 2 and the pressure in the aquifer at the elastic capacity $S=1 \times 10^{-4}$. The dashed vertical line shows the amplitude ratio $x_{0} / h_{0} \sim 1$ at the period $\tau=3 \mathrm{~h}$ and the water transmissibility $T=7.5 \times 10^{-5} \mathrm{~m}^{2} / \mathrm{s}\left(6.48 \mathrm{~m}^{2} /\right.$ day $) ; M_{2}$ and $O_{1}$ are the tidal waves with the periods $12.42 \mathrm{~h}$ and $25.82 \mathrm{~h}$, respectively. 

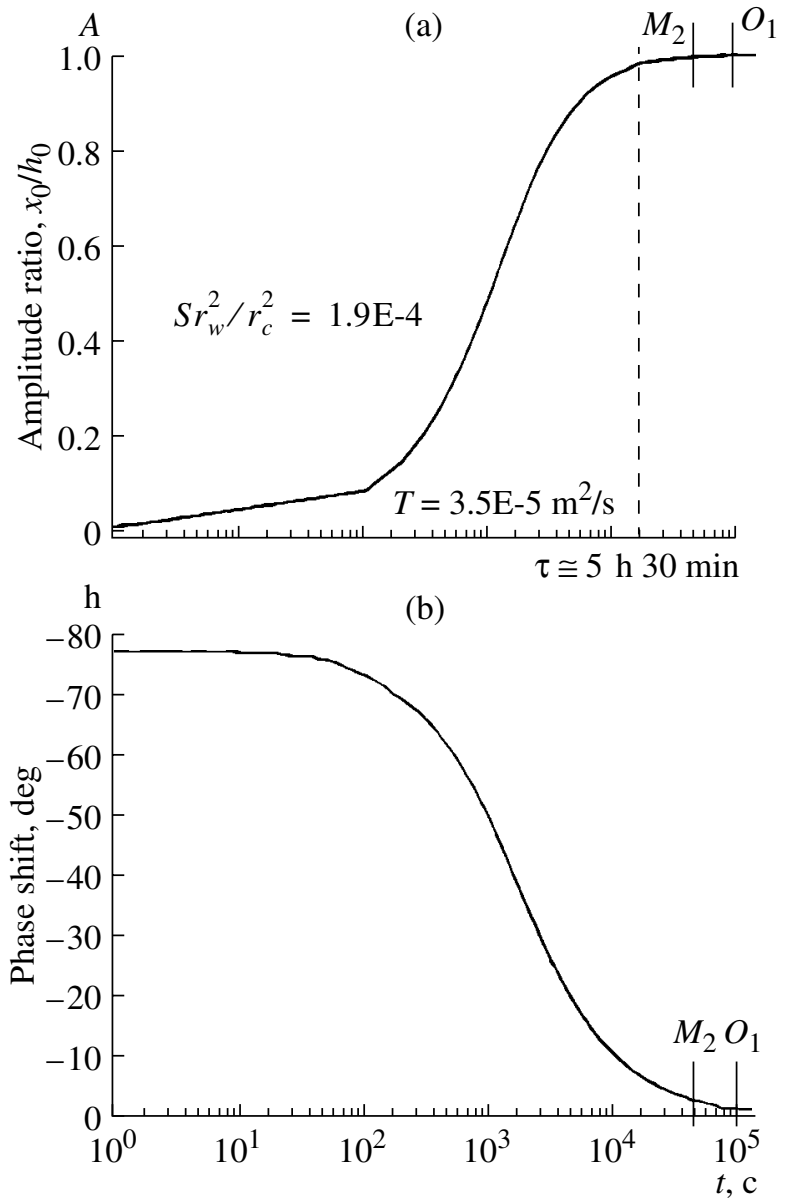

Fig. 6. Plots of (a) the amplitude ratio $x_{0} / h_{0}$ and (b) the phase shift $\eta$ between the water-level variations in borehole No. 2 and the pressure in the aquifer at the values $T=3.5 \times$ $10^{-5} \mathrm{~m}^{2} / \mathrm{s}\left(3 \mathrm{~m}^{2} /\right.$ day $)$ and $\mu^{*}=S=2.3 \times 10^{-4}$ obtained from the data of borehole testing. The dashed vertical line shows the amplitude ratio $x_{0} / h_{0} \sim 1$ at the period $\tau=5 \mathrm{~h} 30 \mathrm{~min}$.

variations to water-level variations (Fig. 3). The value $T=$ $6.48 \mathrm{~m}^{2} /$ day was chosen on the basis of attaining the amplitude ratio $x_{0} / h_{0} \approx 1$ at a period of $\sim 3 \mathrm{~h}$ and approaching the phase shift $\eta$ to $0^{\circ}$.

If the values $T=3.0 \mathrm{~m}^{2} / \mathrm{day}$ and $S=2.3 \times 10^{-4}$ obtained from the data of experimental-filtration works are used, the amplitude ratio $x_{0} / h_{0} \approx 1$ and the total response of the water level to periodic pressure variations in the stratum are attained at a larger period $\tau=5 \mathrm{~h} 30 \mathrm{~min}$ (Fig. 6). This can be associated with the fact that the experimental-filtration works were carried out immediately after the borehole drilling during $12 \mathrm{~h}$ and did not lead to a complete colmatage of cracks and caverns in water-bearing rocks after the drilling. Evidently, this situation is responsible for the relatively underestimated value of the water transmissibility of the Aleksin-Tarusa aquifer obtained from the data of experimental-filtration works.

\section{CONCLUSIONS}

Investigations of the barometric and tidal responses of the water level in borehole No. 2 suggest the presence of statically isolated conditions in the stratum-borehole system under consideration at periods of $\geq 3 \mathrm{~h}$ with periodic variations in the pore pressure caused by changes in the stress-strain state of the geological medium. The barometric effectiveness $E_{b}=0.65 \mathrm{~cm} / \mathrm{hPa}$, the tidal sensitivity of the water level with respect to the theoretical volume strain $A_{\mathrm{V}}=0.056 \mathrm{~cm} / 10^{-9}$, and the elastic parameters and porosity of water-bearing rocks (Table 2) have been estimated.

Probably, borehole No. 2 will behave as a volume strain meter at periods of $\geq 3 \mathrm{~h}$, and pore-pressure variations caused by the action of geodynamic factors will be recognizable in water-level variations. The volume strain of water-bearing rocks $\Delta \varepsilon$ can be qualitatively estimated from the amplitudes of the revealed anomalous changes in the water level and the quantity $A_{v}$.

At the same time, the lower boundary of the periods, at which statically isolated conditions occur in borehole No. 2, has not been determined; however, by analogy with other boreholes, characterized by a statically isolated response of the water level and similar filtration and elastic parameters of water-bearing rocks, this boundary, supposedly, is not smaller than a few hundreds of hours. For a more exact determination of this boundary, the series of observations must be at least 1-2-year long.

The high-frequency range in periods from a few minutes to 12 hours is identified from changes in the barometric effectiveness depending on the period of variations. This range is characterized by an unstable barometric response of the water level due to the inertial character of the water exchange in the stratum-borehole system in the range of periods $<3 \mathrm{~h}$ and, possibly, due to anthropogenic noise. In this range of periods, it is difficult to estimate the strain of the water-saturated stratum controlled by the borehole during periodic changes in the stress-strain state of the geological medium.

Modeling of the effect of the water exchange in the stratum-borehole system [Hsieh et al., 1987] with allowance for the borehole design and with the use of calculated and experimentally determined values of the water transmissibility $T$ and the elastic capacity $S$, as well as a comparison of the results obtained with the behavior of the amplitude transfer function from atmospheric-pressure variations to water-level variations, have made it possible to refine the value of the water transmissibility of the Aleksin-Tarusa aquifer for the considered period of level-gauge observations ( $T=6.48 \mathrm{~m}^{2} /$ day $)$.

To check the inertial properties of the stratum-borehole system, the range of periods, in which the barometric response is unstable, must be periodically checked, as the database of standard observations becomes increasingly extensive. 


\section{REFERENCES}

1. A. A. Bagmet, M. I. Bagmet, V. L. Barabanov, et al., "Study of Earth Tide Variations in the Groundwater Level in the Obninsk Hole," Izv. Akad. Nauk SSSR, Fiz Zemli, No. 11, 84-95 (1989).

2. S. V. Boldina and G. N. Kopylova, "Estimation of the Inertial Effect of Water Exchange between a Borehole and a Reservoir of Groundwater," in Vestnik KRAUNTs, Series Earth Sciences, No. 2., Iss. 8, 112-119 (2006) [in Russian].

3. P. Hsieh, J. Bredehoeft, and J. Farr, "Determination of Aquifer Transmissivity from Earth-Tide Analysis," Water Resour. Res 23, 1824-1832 (1987).

4. G. N. Kopylova, "Water-Level Variations in Borehole YuZ-5, Kamchatka Caused by Earthquakes," Vulkanol. Seismol., No. 6, 52-64 (2006).

5. G. N. Kopylova and S. V. Boldina, "Estimation of Poroelastic Parameters of a Groundwater Reservoir (from Data of Level-Gauge observations in Borehole YuZ-5, Kamchatka)," Vulkanol. Seismol., No. 2, 17-28 (2006).

6. G. N. Kopylova, G. V. Kulikov, and V. M. Timofeev, "Estimation of the State and Prospects for Development of the Hydrogeodeformation Monitoring of Seismically Active Regions of Russia," Razvedka I Okhrana Nedr, No. 11, 75-83 (2007).
7. A. A. Lyubushin, Analysis of Data of Systems of Geophysical and Ecological Monitoring (Nauka, Moscow, 2007) [in Russian].

8. A. A. Lyubushin (Jr.), V. A. Malygin, and O. S. Kazantseva, "Monitoring of Tidal Variations in the Groundwater Level in a Group of Aquifers," Fiz. Zemli, No. 4, 52-64 (1997) [Izvestiya, Phys. Solid Earth (1997)].

9. P. Melchior, The Earth Tides (Oxford, 1966; Mir, Moscow, 1968).

10. J. R. Rice and M. P. Cleary, "Some Basic Stress-Diffusion Solutions for Fluid Saturated Elastic Porous Media with Compressible Constituents," Rev. Geophys. Space Phys. 14, 227-241 (1976).

11. E. A. Roeloffs, "Hydrologic Precursors to Earthquakes: A Review," Pure Appl. Geophys. 126, 199-209 (1988).

12. S. Rojstaczer, "Intermediate period Response of Water Levels in Wells to Crustal Strain: Sensitivity and Noise Level," J. Geophys. Res 93, 13619-13634 (1988).

13. S. Rojstaczer and D. S. Agnew, "The Influence of Formation Material Properties on the Response of Water Levels in Wells to Earth Tides and Atmospheric Loading," J. Geophys. Res. 94, 12403-12411 (1989).

14. H. G. Wenzel, "Earth Tide Analysis Package ETERNA 3.0," BIM, No. 118, 8719-8721 (1994). 